\title{
PENGARUH POPULASI TANAMAN DAN DOSIS BIOFERTILIZER EXTRAGEN TERHADAP PERTUMBUHAN DAN HASIL TANAMAN WORTEL (Daucus carota L.) DI DATARAN RENDAH
}

\section{THE EFFECT OF PLANT POPULATION AND RATE OF BIOFERTILIZER EXTRAGEN ON GROWTH AND YIELD OF CARROT (Daucus carota L.) ON THE LOWLAND}

\author{
Riema Rimanda Putri ${ }^{1}$, Aluh Nikmatullah ${ }^{{ }^{*}}$, Herman Suheri ${ }^{1}$ \\ ${ }^{1}$ Program Studi Agroekoteknologi Fakultas Pertanian Universitas Mataram, Mataram, Indonesia \\ *Email Penulis korespondensi:aluh_nikmatullah@unram.ac.id
}

\begin{abstract}
Abstrak
Penelitian ini bertujuan untuk mengetahui pengaruh populasi tanaman, dosis biofertilizer ExtraGEN dan interaksinya terhadap pertumbuhan dan hasil tanaman wortel (Daucus carota L.) di dataran rendah. Percobaan dilakukan di lahan percobaan Universitas Mataram di Narmada, Lombok Barat, NTB dengan ketinggian $136 \mathrm{~m}$ dpl pada bulan Mei sampai bulan Juli 2019. Metode yang digunakan pada penelitian ini adalah metode eksperimental berdasarkan Rancangan Acak Lengkap (RAL) faktorial, yang terdiri atas 2 faktor yaitu, populasi tanaman dan dosis biofertilizer ExtraGEN. Populasi tanaman terdiri atas 3 aras : 1 tanaman wortel/polybag, 3 tanaman wortel/polybag dan 5 tanaman wortel/polybag. Dosis biofertilizer ExtraGEN sebanyak 4 aras yaitu tanpa biofertilizer ExtraGEN (kontrol), dosis biofertilizer ExtraGEN $100 \mathrm{ml} /$ polybag, $200 \mathrm{ml} /$ polybag dan $400 \mathrm{ml} /$ polybag. Secara keseluruhan diperoleh 12 kombinasi perlakuan yang diulang 5 kali. Data yang diperoleh dianalisis dengan Analisis Sidik Ragam atau ANOVA pada taraf nyata $5 \%$ dan untuk parameter yang memperlihatkan adanya pengaruh perlakuan dilakukan uji lanjut dengan uji Beda Nyata Jujur (BNJ) pada taraf nyata 5\%. Hasil penelitian menunjukkan bahwa populasi tanaman berpengaruh terhadap laju pertambahan panjang tangkai daun, berat biomasa segar total umbi/polybag dan berat biomasa kering total umbi/polybag, tetapi tidak berpengaruh terhadap parameter lainnya. Semakin tinggi populasi tanaman, maka laju pertambahan panjang tangkai daun semakin rendah namun, berat biomasa segar total umbi dan berat biomasa kering total umbi semakin tinggi. Berat biomasa per tanaman diperoleh masingmasing 4,07 g populasi 1 tanaman/polybag, $1,37 \mathrm{~g}$ populasi 3 tanaman/polybag dan $0,56 \mathrm{~g}$ populasi 5 tanaman/polybag. Dosis biofertilizer ExtraGEN tidak berpengaruh terhadap pertumbuhan dan hasil tanaman wortel di dataran rendah.

Kata kunci: Wortel, Populasi Tanaman, Dosis, ExtraGEN.
\end{abstract}

\begin{abstract}
A research with an aim to determine the effect of plant population, rate of biofertilizer ExtraGEN and their interaction on the growth and yield of carrot (Daucus carota L.) plants on the lowland was conducted. The experiment was carried out in the University of Mataram experimental field located in Narmada, West Lombok, NTB at an altitude of $136 \mathrm{~m}$ above the sea level from May to July 2019. The research used a Completely Randomized Factorial Design, consisting of 2 factors, namely the plant population and rate of biofertilizer ExtraGEN. The plant population consisted of 3 level : 1 plant/polybag, 3 plants/ polybag and 5 plants/polybag. The rate of biofertilizer ExtraGEN consisted of 4 levels: without biofertilizer ExtraGEN (control), with $100 \mathrm{ml} /$ polybag biofertilizer ExtraGEN, with $200 \mathrm{ml} /$ polybag biofertilizer ExtraGEN, and with $400 \mathrm{ml} /$ polybag biofertilizer ExtraGEN. The combinations resulted in 12 interactions which were repeated 5 times. The data obtained were analyzed using Analysis of Variance (ANOVA) at $5 \%$ significant level and followed by an Honestly Significant Difference (HSD) at the same level. The results showed that plant population affected the rate of increase in the length of petioles, total fresh weight of the roots/polybag and total dry weight of roots/polybag, but did not affect other parameters. Higher the plant population, lowered the rate of increase in length of the petioles increased the total weight of fresh roots biomass/polybag and the weight of total dry biomass/ploybag. Biomass weight per plant was obtained 4,07 g population of 1 plant/polybag, $1,37 \mathrm{~g}$ population of 3 plants/polybag and $0,56 \mathrm{~g}$ population of 5 plants/polybag. The rates of biofertilizer ExtraGEN did not affect the growth and yield of carrot plants on the lowland.
\end{abstract}

Keywords : carrot, plant population, dosage, ExtraGEN 


\section{PENDAHULUAN}

Selama ini, fokus pengembangan produksi pangan adalah di lahan sawah sedangkan Indonesia masih memiliki potensi lahan pekarangan untuk produksi pangan mencapai 10,3 juta hektar, atau kurang lebih 14\% dari luas lahan pertanian (Badan Litbang Pertanian, 2011). Lahan pekarangan tersebut berpotensi untuk dimanfaatkan untuk menghasilkan pangan bagi keluarga. Berdasarkan potensi tersebut, pemerintah Indonesia melalui Kementerian Pertanian mencanangkan kegiatan optimalisasi pemanfaatan pekarangan dengan program Kawasan Rumah Pangan Lestari (KRPL) (Imansuri dkk, 2016). antara lain dengan menanam beberapa sayuran sehingga potensial untuk dikembangkan pada KRPL yaitu wortel (Daucus carota L).

Wortel mengandung $\alpha$ - dan $\beta$-karoten, vitamin $\mathrm{B}$, vitamin $\mathrm{C}$ dan mineral terutama kalsium dan fosfor. Setiap 100 gram umbi wortel segar mengandung 42,2 kalori, $9 \mathrm{~g}$ karbohidrat, 0,2 g lemak, $1 \mathrm{~g}$ protein, $33 \mathrm{mg}$ kalsium, $35 \mathrm{mg}$ fosfor, 0,66 mg besi, 835 SI vitamin A, 0,6 mg vitamin B dan 1,9 mg vitamin C (Direktorat Gizi Depkes RI, 1979). Dengan kandungannya tersebut, dapat membantu menurunkan tekanan darah pada penderita tekanan darah tinggi, mengencangkan kulit muka, menurunkan kolestrol dalam darah, mencegah kanker pankreas, kanker paru-paru, hepatitis dan mencegah stroke (Mehrir, 2012).

Pada program KRPL, budidaya tanaman umumnya dilakukan di dalam pot (polybag) yang keberhasilannya antara lain ditentukan oleh media tanam yang digunakan. Ketersediaan media tanam menjadi kendala untuk keberlanjutan budidaya, terutama di perkotaan. Oleh karena itu, perlu penggunaan media tanam yang efisien, antara lain dengan menanam lebih dari 1 tanaman per polybag. Jumlah tanaman per polybag mempengaruhi kepadatan populasi tanaman yang akan dapat menyebabkan persaingan dalam intersepsi radiasi sinar matahari, absorbsi air dan unsur hara serta pengambilan $\mathrm{CO}_{2}$ dan $\mathrm{O}_{2}$. Jika populasinya jarang, persaingan akan lebih sedikit akan tetapi kebutuhan akan media tanam dan ruang menjadi lebih besar (Indrayanti, 2010).

Budidaya wortel umumnya dilakukan di dataran tinggi (ketinggian 1000-1500 m dpl). Akan tetapi terdapat beberapa varietas wortel yang mampu berproduksi di dataran rendah $( \pm 110 \mathrm{~m} \mathrm{dpl})$ dan dataran medium medium $(400-800 \mathrm{~m} \mathrm{dpl})$, seperti varietas New Nantes dan New Kuroda (Departemen Pertanian RI, 2005). Kedua varietas tersebut dapat beradaptasi terhadap suhu udara sampai dengan $30^{\circ} \mathrm{C}$ dan suhu tanah hingga $28^{\circ} \mathrm{C}$ (Aazami dan Muhammadi, 2008). Selain kedua varietas tersebut, Zawani dkk (2018), menunjukkan bahwa wortel varietas Gundaling dapat tumbuh dan menghasilkan umbi di dataran rendah meskipun belum optimal.

Salah satu teknologi yang mungkin dapat meningkatkan hasil wortel di dataran rendah adalah perlakuan dengan biofertilizer ExtraGEN. Biofertilizer ExtraGEN merupakan pupuk hayati yang mengandung mikroorganisme pelarut $\mathrm{P}$ dan penambat $\mathrm{N}$ dari udara, zat pengatur tumbuh (auksin, giberelin dan sitokinin), serta unsur hara makro dan mikro (Anonim, 2013).

Berdasarkan uraian tersebut maka dilakukan penelitian tentang "Pengaruh Populasi Tanaman dan Dosis Biofertilizer ExtraGEN terhadap Pertumbuhan dan Hasil Tanaman Wortel (Daucus carota L.) di Dataran Rendah" 


\section{METODE PENELITIAN}

\section{Tempat dan Waktu Percobaan}

Penelitian ini dilakukan di lahan percobaan Universitas Mataram yang bertempat di Narmada, Lombok Barat, NTB dengan ketinggian $136 \mathrm{~m}$ dpl. Penelitian ini dilaksanakan pada bulan Mei sampai dengan bulan Juli 2019.

\section{Rancangan Percobaan}

Percobaan dirancang dengan Rancangan Acak Lengkap (RAL) faktorial, yang terdiri atas 2 faktor. Faktor pertama adalah populasi tanaman (P) dengan 3 taraf yaitu p1 (1 tanaman wortel/polybag), p2 (3 tanaman wortel/polybag) dan p3 (5 tanaman wortel/polybag). Faktor kedua adalah dosis biofertilizer ExtraGEN (D) sebanyak 4 taraf yaitu d0 (tanpa biofertilizer ExtraGEN (kontrol), d1 (dosis $100 \mathrm{ml} /$ polybag), d2 (dosis $200 \mathrm{ml} /$ polybag) dan $\mathrm{d} 3$ (dosis $400 \mathrm{ml} /$ polybag). Interaksi kedua perlakuan dikombinasikan sehingga diperoleh 12 perlakuan. Setiap perlakuan diulang 5 kali.

\section{Pelaksanaan Percobaan}

Percobaan dilaksanakan mulai dari persiapan media tanam. Media tanam yang digunakan yaitu campuran tanah topsoil dan sekam yang dicampur dengan perbandingan 1:1. Benih yang digunakan dalam percobaan ini adalah benih wortel varietas Lokal Berastagi tipe Nantes. Benih wortel langsung ditanam (disebar) tanpa melalui persemaian terlebih dahulu pada kedalaman $2 \mathrm{~cm}$. Waktu penyiraman dilakukan pada pagi dan sore hari dan dilakukan sejak penanaman hingga tanaman menghasilkan umbi. Penjarangan tanaman wortel dilakukan pada saat tanaman berumur 3 minggu setelah tanam dan penyiangan dilakukan 2 minggu sekali seminggu dengan cara mencabut gulma-gulma yang tumbuh di sekitar tanaman wortel.

Pemupukan dilakukan dengan pupuk kandang ayam dengan dosis 115 gram/polybag yaitu pada saat 0 dan 45 hari setelah tanam (hst). Pemupukan dengan biofertilizer ExtraGEN dilakukan 5 kali yaitu pada saat tanaman berumur 15, 30, 45, dan 60 HST dengan dosis 100, 200 dan $400 \mathrm{ml} /$ polybag. Pengendalian hama dan penyakit tanaman dilakukan secara hayati menggunakan jamur Metarhizium anisopliae dan Beauveria bassiana Pengendalian secara mekanis yaitu dengan membuang hama yang ada disekitar tanaman. Panen dilakukan pada saat tanaman wortel berumur 90 HST dengan cara mencabut seluruh tanaman bersama umbinya.

\section{Variabel Pengamatan}

Variabel yang diamati pada penelitian ini meliputi pertumbuhan panjang tangkai daun, laju pertumbuhan jumlah daun, berat biomasa segar total tanaman, berat biomasa segar umbi, berat biomasa kering tajuk, berat biomasa kering umbi, berat biomasa segar tajuk, berat biomasa kering total tanaman, berat biomasa total segar umbi/polybag diameter atas umbi, diameter tengah umbi,diameter bawah umbi, panjang umbi, kekerasan umbi, kemanisan umbi, dan perbandingan antara korteks dan stele umbi.

\section{Analisis Data}

Data hasil percobaan dianalisis menggunakan sidik ragam pada taraf nyata $5 \%$. Jika ada perlakuan yang berbeda nyata, maka dilakukan diuji lanjut dengan menggunakan (BNJ) pada taraf nyata $5 \%$. 


\section{HASIL DAN PEMBAHASAN}

\section{Hasil Pengamatan}

Hasil sidik ragam pengaruh jenis, dosis dan interaksi pupuk organik terhadap beberapa parameter tanaman wortel yang dirangkum pada Tabel 1.

Berdasarkan Tabel 1. menunjukkan bahwa populasi tanaman, dosis biofertilizer ExtraGEN dan interaksi kedua faktor tersebut tidak berpengaruh terhadap semua parameter pertumbuhan tanaman wortel di dataran rendah. Namun, populasi tanaman berpengaruh terhadap laju pertambahan panjang tangkai daun, berat biomasa segar total umbi/polybag dan berat biomasa kering umbi/polybag.

Tabel 1. Rekapitulasi Hasil Analisis Sidik Ragam Pengaruh Populasi Tanaman, Dosis

Biofertilizer ExtraGEN dan Interaksinya terhadap Pertumbuhan dan Hasil Tanaman Wortel di Dataran Rendah.

\begin{tabular}{|c|c|c|c|}
\hline \multirow[t]{2}{*}{ Parameter yang diamati } & \multicolumn{3}{|c|}{ Sumber Keragaman } \\
\hline & Populasi & Dosis & Populasi x Dosis \\
\hline Laju Pertambahan Panjang Tangkai & $\mathrm{S}$ & NS & $\mathrm{NS}$ \\
\hline Daun & & & \\
\hline Laju Pertambahan Jumlah Daun & NS & NS & NS \\
\hline Berat Biomasa Segar Umbi & NS & NS & NS \\
\hline Berat Biomasa Segar Tajuk & NS & NS & NS \\
\hline Berat Biomasa Kering Umbi & NS & NS & NS \\
\hline Berat Biomasa Kering Tajuk & NS & NS & NS \\
\hline Berat Biomasa Segar Total /Tanaman & NS & NS & NS \\
\hline Berat Biomasa Kering Total & NS & NS & NS \\
\hline /Tanaman & & & \\
\hline Berat Biomasa Segar Umbi /Polybag & $\mathrm{S}$ & NS & NS \\
\hline Berat Biomasa Kering Umbi /Polybag & $\mathrm{S}$ & NS & NS \\
\hline Panjang Umbi & NS & NS & NS \\
\hline Diameter Atas Umbi & NS & NS & NS \\
\hline Diameter Tengah Umbi & NS & NS & NS \\
\hline Diameter Bawah Umbi & NS & NS & NS \\
\hline Kekerasan Umbi & NS & NS & NS \\
\hline Kemanisan Umbi & NS & NS & NS \\
\hline Selisih Korteks Dengan Stele & NS & NS & NS \\
\hline
\end{tabular}

Keterangan : $\mathrm{S}=$ Significant, NS $=$ Non Significant.

Tabel 2 menunjukkan bahwa populasi 1 tanaman/polybag memiliki laju nilai $3,26 \mathrm{~cm}$ setiap 2 minggu yang merupakan laju tertinggi, populasi 3 tanaman/polybag menghasilkan laju $2,25 \mathrm{~cm}$ setiap 2 minggu dan populasi 5 tanaman/polybag menghasilkan laju terendah yaitu $2,01 \mathrm{~cm}$ setiap 2 minggu. Populasi tanaman tidak berpengaruh terhadap laju pertambahan jumlah daun, namun ada kecenderungan populasi 1 tanaman/polybag menghasilkan jumlah daun lebih tinggi yaitu 1,71 helai setiap 2 minggu dan populasi 3 tanaman/polybag memiliki jumlah daun terendah yaitu 1,59 helai setiap 2 minggu.

Seperti halnya populasi tanaman, dosis biofertilizer ExtraGEN tidak berpengaruh terhadap laju pertambahan panjang tangkai daun dan laju pertambahan jumlah daun. Meskipun demikian, perlakuan tanpa biofertlizer ExtraGEN (dosis $0 \mathrm{ml} / \mathrm{L}$ ) paling tinggi cenderung menghasilkan laju pertambahan panjang tangkai daun yaitu $5,52 \mathrm{~cm}$ setiap 2 minggu dan dosis biofertilizer ExtraGEN $100 \mathrm{ml} / \mathrm{L}$ memiliki nilai 
terendah yaitu 3,98 $\mathrm{cm}$ setiap 2 minggu. Dosis biofertilizer ExtraGEN $100 \mathrm{ml} / \mathrm{L}$ memiliki nilai jumlah daun lebih tinggi yaitu 2,38 helai setiap 2 minggu dan dosis biofertilizer ExtraGEN $400 \mathrm{ml} / \mathrm{L}$ menghasilkan nilai jumlah daun terendah yaitu 2,08 helai setiap 2 minggu.

Perlakuan populasi tanaman dan dosis biofertilizer ExtraGEN tidak berpengaruh terhadap berat biomasa segar dan kering total tanaman. Meskipun demikian, populasi 3 tanaman/polybag cendrung menghasilkan berat biomasa lebih tinggi yaitu 9,04 $\mathrm{g}$ dan $1,13 \mathrm{~g}$. Berat biomasa terendah populasi 5 tanaman/polybag yaitu 6,53 dan $0,57 \mathrm{~g}$. Pada dosis biofertilizer ExtraGEN $100 \mathrm{ml} / \mathrm{L}$ menghasilkan berat biomasa segar total tanaman lebih tinggi yaitu 8,62 dan berat biomasa kering total tanaman tertinggi pada perlakuan tanpa biofertilizer ExtraGEN (dosis $0 \mathrm{ml} / \mathrm{L}$ ) yaitu $0,96 \mathrm{~g}$. Sedangkan, berat biomasa terendah dosis biofertilizer ExtraGEN $400 \mathrm{ml} / \mathrm{L}$ yaitu $5,85 \mathrm{~g}$ berat biomasa segar total tanaman dan $0,55 \mathrm{~g}$ berat biomasa kering total tanaman.

\section{Pengaruh Populasi Tanaman dan Dosis Biofertilizer ExtraGEN terhadap Pertumbuhan Tanaman Wortel}

Tabel 2. Laju Pertambahan Panjang Tangkai Daun, Laju Pertambahan Jumlah Daun, Berat Biomasa Segar Total Tanaman dan Berat Biomasa Kering Total Tanaman pada Perlakuan Populasi Tanaman dan Dosis Biofertilizer ExtraGEN

\begin{tabular}{lcccc}
\hline Perlakuan & LPPTD $(\mathrm{cm} / 2$ minggu $)$ & $\begin{array}{c}\text { LPJD } \\
\text { (helai/2 minggu })\end{array}$ & $\begin{array}{c}\text { BBSTT } \\
(\mathrm{g})\end{array}$ & $\begin{array}{c}\text { BBKTT } \\
(\mathrm{g})\end{array}$ \\
\hline $\begin{array}{c}\text { Populasi Tanaman } \\
\text { P1 (Populasi 1) }\end{array}$ & $3,26(\mathrm{a})$ & 1,71 & 7,21 & 0,73 \\
P2 (Populasi 3) & $2,25(\mathrm{ab})$ & 1,59 & 9,04 & 1,13 \\
P3 (Populasi 5) & $2,01(\mathrm{~b})$ & 1,67 & 6,53 & 0,57 \\
\hline BNJ & 1,04 & - & - & - \\
\hline Dosis Biofertilizer & & & & \\
D0 $(0 \mathrm{ml} / \mathrm{L})$ & 3,25 & 1,75 & 8,40 & 0,96 \\
D1 $(100 \mathrm{ml} / \mathrm{L})$ & 2,15 & 1,80 & 8,62 & 0,90 \\
D2 $(200 \mathrm{ml} / \mathrm{L})$ & 2,18 & 1,59 & 7,50 & 0,83 \\
D3 $(400 \mathrm{ml} / \mathrm{L})$ & 2,46 & 1,49 & 5,85 & 0,55 \\
\hline Keterangan & & & & \\
\hline
\end{tabular}

Keterangan : LPPTD (Laju Pertambahan Panjang Tangkai Daun), LPJD (Laju Pertambahan Jumlah Daun,

BBSTT (Berat Biomasa Segar Total Tanaman), BBKTT (Berat Biomasa Kering Total Tanaman). 
Tabel 3. Berat Biomasa Segar Umbi, Berat Biomasa Kering Umbi, Berat Biomasa Segar Total Umbi/Polybag dan Berat Biomasa Kering Total Umbi/Polybag pada Perlakuan Populasi Tanaman dan Dosis Biofertilizer ExtraGEN.

\begin{tabular}{lcccc}
\hline \multicolumn{1}{c}{ Perlakuan } & BBSU $(\mathrm{g})$ & BBKU $(\mathrm{g})$ & $\begin{array}{c}\text { BBSTU/P } \\
(\mathrm{g})\end{array}$ & $\begin{array}{c}\text { BBKTU/P } \\
(\mathrm{g})\end{array}$ \\
\hline $\begin{array}{l}\text { Populasi Tanaman } \\
\text { P1 (Populasi 1) }\end{array}$ & 4,07 & 0,73 & $4,07(\mathrm{~b})$ & $0,73(\mathrm{ab})$ \\
P2 (Populasi 3) & 4,12 & 0,34 & $12,38(\mathrm{ab})$ & $3,40(\mathrm{a})$ \\
P3 (Populasi 5) & 2,81 & 0,16 & $14,06(\mathrm{a})$ & $3,20(\mathrm{a})$ \\
BNJ & & & 9,65 & 2,25 \\
\hline$\quad$ Dosis Biofertilizer & & & & \\
D0 (0 ml/L) & 3,78 & 0,29 & 12,27 & 2,25 \\
D1 (100 ml/L) & 4,66 & 0,39 & 10,14 & 2,81 \\
D2 (200 ml/L) & 3,82 & 0,26 & 10,47 & 2,22 \\
D3 (400 ml/L) & 2,42 & 0,16 & 12,21 & 2,54 \\
\hline Kerang
\end{tabular}

Keterangan : Berat Biomasa Segar Umbi (BBSU), Berat Biomasa Kering Umbi (BBKU), Berat Biomasa Segar Total Umbi/Polybag (BBSTU/P) dan Berat Biomasa Kering Total Umbi/Polybag (BBKTU/P).

Tabel 3 menunjukkan bahwa berat biomasa segar dan kering umbi tidak dipengaruhi oleh populasi tanaman. Namun, pada berat biomasa segar dan kering umbi ada kecenderungan populasi 3 tanaman/polybag menghasilkan berat biomasa lebih tinggi yaitu 4,12 g dan 0,34 g. Populasi 5 tanaman/polybag berat biomasa segar dan kering umbi menghasilkan nilai terendah yaitu 2,81 dan $0,16 \mathrm{~g}$. Pada perlakuan dosis biofertilizer ExtraGEN ada kecenderungan dosis $100 \mathrm{ml} / \mathrm{L}$ menghasilkan berat biomasa lebih tinggi pada yaitu 4,66 g dan 0,39 g. Dosis biofertilizer ExtraGEN $400 \mathrm{ml} / \mathrm{L}$ menghasilkan nilai terendah yaitu 2,42 dan $0,16 \mathrm{~g}$.

Populasi tanaman berpengaruh terhadap berat biomasa segar dan kering total umbi/polybag. Populasi 3 tanaman/polybag berpengaruh terhadap berat biomasa segar umbi/polybag memiliki berat biomasa yaitu 12,38 g. Meskipun demikian, populasi 5 tanaman/ polybag menghasilkan berat biomasa lebih tinggi yaitu 14,06 $\mathrm{g}$ dan populasi 1 tanaman/polybag menghasilkan berat biomasa paling rendah yaitu 4,07 g. Populasi 1 tanaman/polybag berpengaruh terhadap berat biomasa kering total umbi/polybag menghasilkan berat biomasa yaitu $0,73 \mathrm{~g}$ dan merupakan berat biomasa terendah diantara populasi 3 dan 5 tanaman/polybag. Populasi 3 tanaman/polybag menghasilkan berat biomasa lebih tinggi yaitu 3,40 g. Jika dihitung berat biomasa per tanaman, maka diperoleh masing-masing 4,07 $\mathrm{g}$ populasi 1 tanaman/polybag, 1,37 $\mathrm{g}$ populasi 3 tanaman/polybag dan $0,56 \mathrm{~g}$ populasi 5 tanaman/polybag.

Dosis biofertilizer ExtraGEN tidak berpengaruh terhadap berat biomasa segar dan kering total umbi/polybag. Namun ada kecendrungan perlakuan tanpa biofertlizer ExtraGEN (dosis $0 \mathrm{ml} / \mathrm{L}$ ) menghasilkan berat biomasa segar total umbi/polybag lebih tinggi yaitu 12,27 g dan perlakuan dosis biofertilizer ExtraGEN $100 \mathrm{ml} / \mathrm{L}$ menghasilkan nilai terendah yaitu $10,14 \mathrm{~g}$. Sedangkan, dosis $100 \mathrm{ml} / \mathrm{L}$ berat biomasa kering total tanaman/polybag Perlakuan dosis $100 \mathrm{ml} / \mathrm{L}$ menghasilkan berat biomasa tertinggi yaitu 2,81 $\mathrm{g}$ dan dosis biofertilizer ExtraGEN $200 \mathrm{ml} / \mathrm{L}$ terendah yaitu 2,22 $\mathrm{g}$. 


\section{Pengaruh Populasi Tanaman dan Dosis Biofertilizer ExtraGEN terhadap Hasil Tanaman Wortel}

Tabel 4. Kekerasan Umbi, Kemanisan Umbi, Panjang Umbi dan Perbandingan Korteks dengan Stele Umbi pada Populasi Tanaman dan Dosis Biofertilizer ExtraGEN

\begin{tabular}{lcccc}
\hline \multicolumn{1}{c}{ Perlakuan } & KKU & KU & PU (cm) & K/S \\
\hline Populasi Tanaman & & & & \\
P1 (Populasi 1) & 2,23 & 7,80 & 5,07 & $0,20: 1$ \\
P2 (Populasi 3) & 1,23 & 8,32 & 4,05 & $0,19: 1$ \\
P3 (Populasi 5) & 1,54 & 6,08 & 3,86 & $0,22: 1$ \\
\hline Dosis Biofertilizer & & & & \\
D0 (0 ml/L) & 1,68 & 7,63 & 4,78 & $0,28: 1$ \\
D1 (100 ml/L) & 1,75 & 7,57 & 4,65 & $0,18: 1$ \\
D2 (200 ml/L) & 1,82 & 7,80 & 4,65 & $0,18: 1$ \\
D3 (400 ml/L) & 1,43 & 6,60 & 3,71 & $0,14: 1$ \\
\hline Ketrang
\end{tabular}

Keterangan : Kekerasan Umbi (KKU), Kemanisan Umbi (KU), Panjang Umbi (PU) dan Perbandingan Korteks dengan Stele Umbi (K/S).

Pelakuan populasi tanaman dan dosis biofertilizer ExtraGEN tidak berpengaruh terhadap kekerasan umbi dan kemanisan umbi. Umbi yang dihasilkan dari perlakuan dengan populasi 1 tanaman/polybag cenderung paling keras yaitu $2,23 \mathrm{~kg} / \mathrm{cm}^{2}$ dan populasi 3 tanaman/polybag menghasilkan nilai kekerasan umbi terendah yaitu 1,23 $\mathrm{kg} / \mathrm{cm}^{2}$. Pada kemanisan umbi perlakuan populasi 3 tanaman/polybag cenderung paling manis yaitu $8,32^{\circ}$ Brix dan populasi 5 tanaman/polybag menghasilkan nilai terendah yaitu $6,08^{\circ}$ Brix.

Umbi yang dihasilkan dari perlakuan dengan dosis biofertilizer ExtraGEN 200 $\mathrm{ml} / \mathrm{L}$ cenderung paling keras dan paling manis yaitu $1,82 \mathrm{~kg} / \mathrm{cm}^{2}$ dan $7,80^{\circ}$ Brix. Sedangkan, dosis biofertilizer ExtraGEN $400 \mathrm{ml} / \mathrm{L}$ menghasilkan nilai kekerasan dan kemanisan umbi terendah yaitu masing-masing $1,43 \mathrm{~kg} / \mathrm{cm}^{2}$ dan $6,60^{\circ}$ Brix.

Perbedaan populasi tanaman tidak berpengaruh terhadap panjang umbi dan perbandingan korteks dengan stele umbi yang dihasilkan. Populasi 1 tanaman/polybag cenderung menghasilkan umbi paling panjang yaitu $5,07 \mathrm{~cm}$ dan populasi 5 tanaman/polybag menghasilkan panjang paling pendek yaitu $3,86 \mathrm{~cm}$.

Perlakuan populasi tanaman menghasilkan tanaman dengan korteks : stele yaitu 0,19-0,22 korteks. Perlakuan dosis biofertilizer ExtraGEN menghasilkan umbi dengan panjang umbi $3,71 \mathrm{~cm}-4,78 \mathrm{~cm}$ dan perbandingan korteks : stele yaitu $0,14-0,28$ kali lebih banyak korteks. Ada kecenderungan perlakuan tanpa biofertilizer ExtraGEN (dosis $0 \mathrm{ml} / \mathrm{L}$ ) menghasilkan panjang umbi dan perbandingan korteks dengan stele lebih tinggi yaitu 4,78 $\mathrm{cm}$ dan 0,28. Dosis biofertilizer ExtraGEN $400 \mathrm{ml} / \mathrm{L}$ menghasilkan panjang umbi terendah yaitu $3,71 \mathrm{~cm}$ dan perbandingan korteks dengan stele terendah yaitu 0,14 .

\section{Pembahasan}

Tanaman wortel menyukai suhu udara yang relatif dingin selama pertumbuhannya. Di Indonesia, kondisi tersebut dapat dijumpai di dataran tinggi (800 $1300 \mathrm{~m} \mathrm{dpl}$ ). Meskipun demikian, Arnedi (2018) menunjukkan bahwa wortel varietas Gundaling dapat dibudidayakan di dataran medium secara organik. Budidayanya menggunakan pupuk kandang ayam dengan dosis 20 ton/Ha menghasilkan tanaman 
dengan perkiraan produksi 33,26 ton/ha. Selain itu, Zawani dkk (2018) menyatakan bahwa wortel varietas Gundaling dapat dibudidayakan di dalam pot/polybag di dataran rendah, meskipun hasilnya masih rendah. Hal ini menunjukkan potensi tanaman wortel untuk ditanam dalam program KRPL di dataran rendah.

Produktivitas dan efisiensi penggunaan media tanam pada budidaya wortel di dataran rendah dalam polybag dapat ditingkatkan dengan mengatur kepadatan atau populasi tanaman. Populasi tanaman yang tinggi akan menghasilkan tanaman dengan jarak yang rapat sehingga mengakibatkan kompetisi yang lebih tinggi dalam mendapatkan ruang tumbuh, air, unsur hara dan cahaya. Safitri (2012) menyatakan bahwa jarak tanam yang terlalu rapat menyebabkan kompetisi dalam memperoleh unsur hara pada lahan menjadi tinggi yang kemudian berdampak pada produksi yang tidak maksimal. Populasi tanaman yang rendah akan menyebabkan kompetisi yang rendah namun tidak efisien dalam penggunaan lahan, ruang tumbuh dan media tanam. Penelitian ini menggunakan polybag dengan diameter $25 \mathrm{~cm}$, sehingga populasi 5 tanaman/polybag menghasilkan jarak antar tanaman satu dengan yang lainnya sekitar 5 x $5 \mathrm{~cm}$, populasi 3 tanaman/polybag menghasilkan jarak antar tanaman sekitar $8 \times 8 \mathrm{~cm}$ dan populasi 1 tanaman/polybag menghasilkan jarak antar tanaman sekitar $25 \times 25 \mathrm{~cm}$. Budidaya tanaman wortel di lapangan umumnya menggunakan jarak tanam yaitu $20 \mathrm{x}$ $10 \mathrm{~cm}$ dengan populasi 2 tanaman per lubang tanam (Taufika 2011). Arnedi (2018), menggunakan jarak tanam $25 \times 20 \mathrm{~cm}$.

Hasil penelitian menunjukkan bahwa semakin banyak populasi tanaman/polybag, maka laju pertambahan panjang tangkai daun semakin rendah. Populasi 1, populasi 3 dan populasi 5 tanaman/polybag terendah yaitu 3,71 cm nilai laju pertumbuhan panjang tangkai daun berturut-turut yaitu $3,26 \mathrm{~cm}, 2,25 \mathrm{~cm}$ dan $2,01 \mathrm{~cm}$ setiap 2 minggu. Hal ini menunjukkan perbedaan tingkat kompetisi atau persaingan antar tanaman dengan populasi 1, 3 dan 5 tanaman/polybag dalam penerimaan cahaya matahari, ruang tumbuh, air dan unsur hara yaitu tanaman yang populasinya paling rendah memiliki kompetisi yang paling sedikit, sedangkan tanaman yang populasinya lebih banyak memiliki kompetisi yang lebih besar. Meskipun populasi tanaman tidak berpengaruh terhadap laju pertambahan jumlah daun, namun ada kecenderungan populasi 1 tanaman/polybag menghasilkan laju pertambahan jumlah daun lebih tinggi yaitu 1,71 helai setiap 2 minggu. Populasi 3 tanaman/ terendah yaitu $3,71 \mathrm{~cm}$ laju pertambahan jumlah daun yaitu 1,59 helai setiap minggu dan populasi 5 tanaman/polybag terendah yaitu $3,71 \mathrm{~cm}$ nilai laju pertambahan jumlah daun 1,67 helai setiap 2 minggu. Artinya, bahwa pada populasi 3 dan 5 tanaman/ polybag terjadi kompetisi antara tanaman di dalam polybag untuk memperoleh air, cahaya, unsur hara dan ruang tumbuh tanaman. Gardner, $d k k$ (1991) yang menyatakan bahwa kerapatan tanaman merupakan faktor yang mempengaruhi pertumbuhan tanaman, karena penyerapan energi matahari oleh permukaan daun yang sangat menentukan pertumbuhan tanaman sangat dipengaruhi oleh kerapatan tanaman. Jika tanaman terlalu rapat, maka bagian tanaman yang akan menerima cahaya matahari berkurang karena saling menutupi, sehingga akan berpengaruh terhadap pertumbuhan vegetatif dan menurunkan hasil panen akibat menurunnya laju fotosintesis dan perkembangan daun.

Populasi tanaman tidak berpengaruh nyata terhadap berat biomasa segar umbi, namun ada kecenderungan populasi 3 tanaman/polybag terendah yaitu $3,71 \mathrm{~cm}$ berat lebih tinggi yaitu $4,12 \mathrm{~g}$, populasi 1 tanaman/polybag terendah yaitu $3,71 \mathrm{~cm}$ berat biomasa segar 4,07 g dan populasi 5 tanaman/polybag memiliki nilai lebih rendah yaitu 2,81 g. Artinya, hubungan populasi dengan hasil tanaman yaitu semakin kompetitif ukuran umbinya cenderung paling kecil. Meskipun demikian, ada perbedaan yang nyata 
antara hasil tanaman/polybag pada populasi 1, populasi 3 dan populasi 5 tanaman/polybag menghasilkan berat biomasa segar total umbi/polybag masing-masing yaitu 4,07 g, 12,38 g dan 14,06 g. Populasi 5 menghasilkan hasil yang paling tinggi dibandingkan populasi 1 dan 3 tanaman/polybag. Hal ini menunjukkan bahwa semakin banyak populasi tanaman/polybag maka semakin besar hasil per satuan luas yang akan diperoleh. Gardner dkk (1991), mengungkapkan bahwa populasi tanaman mempunyai hubungan erat dengan hasil tanaman. Pramitasari (2014), menunjukkan bahwa tingkat kepadatan atau populasi yang semakin banyak menghasilkan bobot segar panen maupun bobot segar konsumsi akan semakin besar.

Penelitian Zawani dkk (2015) menunjukkan bahwa hasil yang diperoleh dari varietas Gundaling di dataran rendah masih rendah, sehingga pada penelitian ini, Perlakuan dosis biofertilizer ExtraGEN diharapkan dapat meningkatkan pertumbuhan dan hasil tanaman wortel di dataran rendah. Biofertilizer ExtraGEN mengandung mikroorganisme, unsur hara dan zpt yang bermanfaat bagi pertumbuhan tanaman. Mikroorganisme tersebut yaitu Pseudomonas, Bacillus megaterium, Azotobacter, yeast, Azospirillum, Actinomycetes dan Lactobacillus. Menurut Marista dkk (2013), Pseudomonas dan Bacillus megaterium merupakan bakteri pelarut $\mathrm{P}$ yang memiliki kemampuan untuk melarutkan unsur $\mathrm{P}$ yang terikat pada unsur lain (Fe, Al, Ca dan $\mathrm{Mg}$ ), sehingga unsur P tersebut menjadi tersedia bagi tanaman. Azospirillum dan Azotobacter mempunyai kemampuan menambat nitrogen dari udara sehingga meningkatkan kadar $\mathrm{N}$ yang dapat diperoleh oleh tanaman. Zat pengatur tumbuh (auksin, giberelin dan sitokinin), unsur hara makro dan mikro yaitu 5,69\% C-organik; 5 ppm Mn; 4 ppm Zn; 29 ppm B; 0,09\%, $\mathrm{P}_{2} \mathrm{O}_{5} ; 185$ ppm Fe; < 1 ppm Cu; 0,6 ppm Mo; 1,6 ppm Co; 0,94\% N total dan $0,49 \% \mathrm{~K}_{2} \mathrm{O}$. Pada penelitian ini, biofertilizer ExtraGEN belum mampu meningkatkan pertumbuhan dan hasil tanaman wortel dalam polybag di dataran rendah. Hal ini diduga disebabkan karena kondisi lingkungan yang Kurang ideal untuk mikroorganisme tersebut dapat tumbuh dan berkembang biak sehingga tidak dapat menjalankan fungsinya. Menurut Asroh (2010), mikroorganisme yang ada dalam larutan pupuk hayati yang disemprotkan pada tanaman atau permukaan tanah, belum tentu dapat hidup dan berkembang karena kondisi lingkungan yang mungkin tidak sesuai. Kondisi yang menentukan pertumbuhan mikroorganisme tersebut antara lain ketersediaan bahan organik sebagai makanan yang mudah di cerna, temperatur udara yang terlalu tinggi, kelembaban yang kurang serta kondisi media tanam yang terlalu poros dengan kadar bahan organik yang rendah.

Mikroorganisme dalam biofertilizer ExtraGEN membutuhkan bahan makanan dari media tanam. Bahan makanan yang diperlukan untuk mikroorganisme dapat tumbuh dan berkembang yaitu bahan organik. Fauzi (2008) menyatakan bahwa bahan organik tanah merupakan penentu produktivitas tanah dan merupakan sumber makanan mikroorganisme dalam tanah melalui reaksi-reaksi kimia. Media tanam yang digunakan pada penelitian ini bahan organiknya rendah, sudah ditambahkan dengan bahan organik dari pupuk kandang ayam tapi mungkin belum cukup. Suryana (2008) menyatakan bahwa suatu tanaman akan tumbuh dan berkembang dengan subur apabila unsur hara yang dibutuhkan ada dan tersedia cukup. Pemberian pupuk kandang ayam dapat meningkatkan kesuburan dan memperbaiki sifat fisik, kimia dan meningkatkan aktivitas biologi tanah serta meningkatkan ketersediaan hara bagi tanaman. Jadi, dengan menambahkan biofertilizer ExtraGEN, terdapat kompetitor tanaman wortel dalam memperoleh bahan makanan dengan mikroorganisme dari dosis yang lebih tinggi, sehingga ada kecenderungan Perlakuan tanpa biofertilizer ExtraGEN (dosis $0 \mathrm{ml} / \mathrm{L}$ ) menghasilkan tanaman dengan pertumbuhan dan hasil yang lebih baik dibandingkan 
dengan pemberian biofertilizer ExtraGEN dengan dosis $200 \mathrm{ml} / \mathrm{L}, 400 \mathrm{ml} / \mathrm{L}$ dan 600 $\mathrm{ml} / \mathrm{L}$. Wahyuningratri (2017) menyatakan bahwa kompetisi terjadi jika dua mikroorganisme memerlukan sesuatu yang sama dan jumlahnya terbatas, seperti nutrisi, ruang tumbuh atau udara. Oleh karena itu, penambahan biofertilizer ExtraGEN seharusnya dilakukan pada tanah dengan kadar bahan organik yang memadai.

Pertumbuhan umbi tanaman wortel dipengaruhi kondisi tanah tempat tumbuh sebagai faktor lingkungan yang sangat menentukan Kualitas umbi. Interaksi antara populasi tanaman dan dosis biofertilizer ExtraGEN tidak berpengaruh terhadap parameter berat biomasa segar umbi, panjang umbi, diameter, kekerasan dan kemanisan umbi serta selisih korteks dengan stele yang merupakan indikator Kualitas hasil panen umbi wortel. Berat biomasa segar umbi yang dihasilkan pada penelitian ini masih sangat rendah yaitu 4,12 g jika dibandingkan dengan hasil pada deskripsi varietas dengan hasil $120 \mathrm{~g}-250 \mathrm{~g}$. Hasil panen yang masih rendah tersebut disebabkan oleh faktor iklim seperti suhu dan curah hujan sangat berperan penting dalam baik buruknya kualitas umbi yang terbentuk. Suhu udara yang terlalu tinggi menyebabkan terganggunya metabolisme tanaman, sehingga pembentukan umbi tidak normal. Tanaman wortel akan menghasilkan umbi yang pendek-pendek (Cahyono, 2002).

Hal ini menunjukkan bahwa, wortel dapat berumbi jika dibudidayakan dalam polybag di dataran rendah meskipun umbi yang dihasilkan tidak maksimal. Hal ini disebabkan oleh faktor lingkungan salah satunya yaitu suhu. Suhu rata-rata di dataran rendah pada saat penelitian ini yaitu berkisar $25,1^{\circ} \mathrm{C}$. Selain itu, ada kemungkinan bahwa suhu tanah pada media tanam wortel meningkat karena disebabkan oleh warna hitam pada polybag kemungkinan menyerap panas yang tinggi dan akan menekan potensi tanaman untuk berkembang dengan baik dan optimal. Samadi (2014), menyatakan bahwa tanaman wortel akan tumbuh baik pada kisaran suhu $15-21,1^{\circ} \mathrm{C}$. Tanaman wortel yang di tanam pada suhu melebihi $21,1^{\circ} \mathrm{C}$ akan menghasilkan umbi yang pendek dan warna umbi yang kurang bagus.

\section{KESIMPULAN DAN SARAN}

\section{Kesimpulan}

1. Populasi tanaman berpengaruh terhadap laju pertambahan panjang tangkai daun, berat biomasa segar total umbi/polybag dan berat biomasa kering total umbi/polybag, tetapi tidak berpengaruh terhadap parameter lainnya. Semakin tinggi populasi tanaman, maka laju pertambahan panjang tangkai daun semakin rendah. Akan tetapi, semakin tinggi populasi tanaman, berat biomasa segar total umbi dan berat biomasa kering total umbi juga semakin tinggi.

2. Dosis biofertilizer ExtraGEN tidak berpengaruh terhadap pertumbuhan dan hasil tanaman wortel di dataran rendah.

\section{Saran}

Berdasarkan hasil penelitian, budidaya wortel dalam polybag di dataran rendah dapat menghasilkan umbi namun belum maksimal. Disarankan agar menanam populasi 5 tanaman/polybag untuk efisiensi penggunaan media tanam serta perlu adanya penelitian kembali tentang komposisi media tanam yang tepat untuk budidaya wortel dalam polybag di dataran rendah. 


\section{DAFTAR PUSTAKA}

Aazami M.A., \& Mohammadi S. (2008). Determination of the Best Temperature and Dry Condition in Carrot. Pakistan Journal of Biological Sciences 11: 15021505.

Anonim. (2013). ExtraGEN Pupuk Hayati Nomor Satu di Dunia. http://www.ExtraGENpusat.com/artikel.php?lang_id=1\&menu_id $=3 . \quad[14$ November 2018].

Arnedi, G. (2018). Respon Tanaman Wortel (Daucus carota L.) Terhadap Pemberian Berbagai Jenis dan Dosis Pupuk Organik di Dataran Medium. [Skripsi, tidak dipublikasikan]. Fakultas Pertanian, Universitas Mataram. Mataram, Indonesia.

Asroh, A. (2010). Pengaruh Takaran Pupuk Kandang dan Interval Pemberian Pupuk Hayati terhadap Pertumbuhan dan Hasil Tanaman Jagung Manis (Zea mays saccharata L). Agronomi 2: 144 - 148.

Badan Litbang Pertanian. (2011). Pengembangan Kawasan Rumah Pangan Lestari (KRPL). Badan Penelitian dan Pengembangan Pertanian. Jakarta.

Cahyono, B. (2002). Wortel, Teknik Budidaya dan Analisis Usaha Tani. Kanisius. Yogyakarta.

Departemen Pertanian R.I. (2005). Pelepasan Wortel Hibrid Viva Kuroda sebagai Varietas Unggul. Kept. Mempen. 502/Ktps/Sk.120/12/2005. Jakarta.

Direktorat Gizi Departemen Kesehatan RI. (1979). Daftar Komposisi Bahan Makanan. BhrataraKarya Aksara. Jakarta.

Fauzi A. (2008). Analisa Kadar Unsur Hara Karbon Organik dan Nitrogen di dalam Tanah Perkebunan Kelapa Sawit Bengkalis Riau. [Skripsi, tidak dipublikasikan]. Fakultas Matematika dan Ilmu Pengetahuan Alam, Universitas Sumatera Utara. Medan, Indonesia.

Gardner F.P., Pearce R.B., \& Mitchell R.L. (1991). Physiology of Crop Plants (Fisiologi Tanaman Budidaya, terjemahan oleh Susilo, H). Universitas Indonesia Press. Jakarta.

Imansuri F., Armaini., \& Sukemi I.S. (2016). Implementasi Program Kawasan Rumah Pangan Lestari Kelurahan Palas Kecamatan Rumbai Kota Madya Pekanbaru. Jurnal Online Mahasiswa Fakultas Pertanian 3: 2-3.

Indrayanti L.A. (2010). Pengaruh Jarak Tanam dan Jumlah Benih Terhadap Pertumbuhan Vegetatif Jagung Muda. Media Sains 2: 37-55.

Kementerian Pertanian. Direktorat Jendral Hortikultura. (2015). Statistika Produksi Hortikultura 2014.

Marista E., Khotimah S., \& Linda R. (2013). Bakteri Pelarut Fosfat Hasil Isolasi Dari Tiga Jenis Tanah Rhizosfer Tanaman Pisah Nipah (Musa paradisiaca Var.Nipah) Di Kota Singkawang. Probiont 2: $93-101$.

Mehrir.

Sejarah

Wortel.

http://www.kawungaten.com/2012/11/Sejarahwortel.html.

[7 Oktober 2018].

Pramitasari H.E., Tatik W., \& Mochammad N. (2014). Pengaruh Dosis Pupuk Nitrogen dan Tingkat Kepadatan Tanaman Terhadap Pertumbuhan dan Hasil Tanaman Kailan (Brassica oleraceae L.). Produksi Tanaman 4: 49 - 56.

Safitri L. S. (2012). Analisis Faktor-Faktor yang Mempengaruhi Produksi Usahatani Wortel Di Kabupaten Cianjur Jawa Barat. [Skripsi, tidak dipublikasikan]. Fakultas Agrobisnis dan Rekayasa Pertanian, Uviversitas Subang. Subang. 
Saliem H.P. (2011). Kawasan Rumah Pangan Lestari (KRPL) Sebagai Solusi Pemantapan Ketahanan Pangan. Pusat Sosial Ekonomi dan Kebijakan Pertanian Balitbangtan. Jakarta. Di dalam: Prosiding Kongres Ilmu Pengetahuan Nasional (KIPNAS). Jakarta.

Samadi B. (2014). Rahasia Budidaya Wortel Sistem Organik. Pustaka Mina. Depok.

Sari R.P., Rosnita., \& Roza Y. (2016). Perilaku Petani Dalam Pelaksanaan Program Kawasan Rumah Pangan Lestari (KRPL) Di Kabupaten Pelalawan. Agro Ekonomi 1: 67-87.

Suryana N.K. (2008). Pengaruh Naungan dan Pupuk Kandang Ayam terhadap Pertumbuhan dan Hasil Tanaman Paprika (Capsicun annum var. Grossum). Agrisains 9: 89 - 95.

Taufika R., Irawati C., Rur M., \& Ardi. (2011). Pengujian Beberapa Dosis Pupuk Organik Cair terhadap Pertumbuhan dan Hasil Tanaman Wortel (Daucus carota L.). Jerami. 4: 175-177.

Wahyuningratri A., Nurul A., Suwasono H. (2017). Pengaruh Konsentrasi dan Frekuensi Pemberian Pupuk Hayati Terhadap Pertumbuhan dan Hasil Cabai Besar (Capsicum annum L.). Produksi Tanaman 5: 84 - 91.

Zawani K., Nikmatullah A., Muslim K.,\& Suryaningsih L. (2018). Pengembangan Baby Wortel Organik di Dataran Rendah. Di dalam: Prosiding PKM-CSR. 1 : 472476. 